\title{
Interactive comment on "The impact of traffic on air quality in Ireland: insights from simultaneous kerbside and sub-urban monitoring of submicron aerosols" by Chunshui Lin et al.
}

\section{Anonymous Referee \#1}

Received and published: 2 March 2020

General comments:

In this study, Lin et al. evaluated the chemical composition and organic aerosol (OA) sources of PM1 monitored simultaneously at a kerbside site and a residential site in Dublin during both non-heating and heating periods. The authors found that vehicle emissions were associated with the significant kerbside increment of black carbon during the non-heating period, but they had a minor impact on air quality at the residential site. Significant contributions of solid fuel burning to OA were observed at both sites during the heating period.

The findings in this study provided valuable information for aerosol scientists to better 
understand the temporal and spatial variations of the concentration, chemical composition, and OA origins of PM1 in Ireland, which could help the formulation of air quality policies and PM1 mitigation strategies in Ireland. Moreover, the paper is well written, and the results are visualized in an appropriate way. Therefore, I recommend it for publication after minor revisions.

Interactive

Specific comments:

1. Line 14, “...sources of submicron aerosols (PM1)..." Actually, the authors performed the source analysis of OA instead of PM1 in this study. Please revise.

2. I think it is more straightforward to use "the non-heating period" and "the heating period" instead of "P1" and "P2" in the manuscript, especially in the figures and tables.

3. Line 149 and 170, the spikes of BC and OA were defined as those with measured concentrations higher than $15 \mu \mathrm{g} / \mathrm{m} 3$ and $5 \mu \mathrm{g} / \mathrm{m} 3$, respectively. What are the criteria to set these two threshold values?

4. Line 186. As mentioned by the authors, the dominant wind direction during the non-heating period was southwest while the city center was located to the north of the residential site. Was there any connecting flow between these two sites? If so, how did the $\mathrm{BC}$ concentration vary at the two sites under the connecting flows?

5. Line 194, Fig. 1c and 1d, another peak concentration was shown in the evening on 29 October, 2018. The authors suggested that these should be due to the residential heating activities. Their impacts on PM1 at residential site are comparable on both dates. However, the burning activity on 31 October showed a greater impact on PM1 than that on the other date at kerbside site. Do the authors have any idea what these burning activities are? Do these kinds of burning activities usually happen during the heating period in Ireland or just special for this sampling period? Are they open-field biomass burning? The reason for me to ask about this is obviously these two burning activities have pulled up the mean values of PM1, OA, BC, NOx etc. at the two 
sites during the heating period. More information about these burning activities will be helpful for the data interpretation and discussion in line 243-250.

6. Line 234, in addition to the low temperatures in the evening, the PBL during the evening was usually lower than that during the day, and thus PBL could also partly contribute to the higher concentration of COA.

7. Line 241 , could the authors estimate the fraction of OOA that were regionally transported to the kerbside site?

8. Line 296, it is not clear what are the typical values of $\mathrm{HOA} / \mathrm{BC}$ for the gasoline vehicles-dominated environment. Please add relevant values and references.

9. Was the second ACSM also equipped with a quadrupole mass spectrometer? How were the Q-ACSMs calibrated?

10. Table $1 \& 2$ can be combined into one. Please add PM1 data in the table. Moreover, numbers in the Table should have the same significant figures as those in the main text of the manuscript and figures.

Several typos:

11. Fig. $4 \mathrm{~d}$, the $O A$ concentration should be 8.1 instead of $8.7 \mu \mathrm{g} / \mathrm{m} 3$.

12. Line 43, "micron-environment" should be "micro-environment".

13. Line 133, should be Crippa et al. (2013).

Interactive comment on Atmos. Chem. Phys. Discuss., https://doi.org/10.5194/acp-2019-1178, 2020. 